\title{
Quinazolinone Derivatives as a Potential Class of Compounds in Malaria Drug Discovery:
}

\section{A Comprehensive Review}

Mohammed Hussen Bule ${ }^{\mathrm{a}}$ Ishtiaq Ahmed ${ }^{\mathrm{b}, \mathrm{d} *}$, Faheem Maqbool ${ }^{\mathrm{c}}$, Muhammad Anjum Zia ${ }^{\mathrm{b}}$, Kuldeep Dhama ${ }^{\mathrm{e}}$, and Hafiz M. N. Iqbal ${ }^{\mathrm{f}}$,

${ }^{a}$ Department of Pharmacy, Clloege of Medicine and Health Sciences, Ambo University, Ambo, Ethiopia; ${ }^{b}$ Department of Biochemistry, University of Agriculture Faisalabad, Pakistan; ${ }^{c}$ Faculty of Pharmaceutical Sciences, Government College University, Faisalabad, Pakistan; ${ }^{d}$ School of Medical Science, Gold Coast campus, Griffith University, Southport QLD 4222, Australia; ${ }^{e}$ Division of Pathology, ICAR-Indian Veterinary Research Institute, Izatnagar, Bareilly 243122, Uttar Pradesh, India; fENCIT - Science, Engineering and Technology School, Tecnologico de Monterrey, Ave. Eugenio Garza Sada 2501, Monterrey, N.L., CP 64849, Mexico; *Corresponding author Tel: +52 (81) 83582000 ext. 5561-115;

E-mail addresses: i.ahmed@griffith.edu.au, hafiz.iqbal@my.westminster.ac.uk \& hafiz.iqbal@itesm.mx

\begin{abstract}
Malaria causes over a million deaths each year (2 per cent of the global total of deaths), with hundreds of millions of clinical episodes per annum. The greatest challenge to malaria control and eradication is the emergence of malaria parasites that are resistant to antimalarial drugs. The development of resistance to conventionally used anti-malarial drugs, such as chloroquine (CQ) and sulfadoxine-pyrimethamine (SP) has been documented. To counter this WHO recommended that artemisinin-based combination therapy (ACT) should be used for treating uncomplicated Plasmodium falciparum malaria to ensure efficacy and reduce the emergence of drug-resistant parasites. Currently available antimalarial drugs are ineffective and their number is declining because of the wide spread resistance. Thus, new antimalarial agent is in urgent demand; however the development of new antimalarial drug presents challenge due to resistance, toxicity, minimal efficacy of those on the pipe line and high cost of drug research. Identification of novel drug targets and design of new chemical compounds acting on new targets is important to control emergence of resistance to existing drugs. In this regard natural product derived synthetic analogues of febrifugines containing quinazolinone scaffold can be considered best. Therefore, quinazolinones, are potential compounds in seeking for novel drugs that act against the malarial pathogen. Hence, in this review compounds containing quinazolinone structure and possessing antimalarial activities are covered.
\end{abstract}




\section{Introduction}

Malaria is symptoms are described in ancient Chinese and Sanskrit medical texts and Hippocrates referred to the disease in the 4th Century BC ${ }^{1}$. It was associated to 'bad air' by the $18^{\text {th }}$ century Italians meaning mala ria from where the name malaria is derived ${ }^{2,3}$. In children under age five malaria accounts for almost 1 in 10 deaths worldwide and 1 in 5 deaths in SubSaharan Africa (SSA), which makes it one among the leading killers ${ }^{4}$. More than $80 \%$ of deaths due to malaria occurs in SSA where $90 \%$ accounts for children under five ${ }^{5}$. Malaria causes over a million deaths each year (2 per cent of the global total of deaths), with hundreds of millions of

clinical episodes per annum ${ }^{3}$. Malaria also places a tremendous burden on national health systems and individual families ${ }^{6}$. In the governmental budget proportions allocated to health system ranges from 5\% in Africa, Asia and the Who Easten Mediterranean Region, to well over $20 \%$ in some countries in Americans ${ }^{7}$. The economic impact of malaria is disproportionately felt by the poor. A study in Tanzania indicated that the death due to acute fever among children of the poorest families was $39 \%$ higher than among the wealthiest children ${ }^{3}$.

The Plasmodium parasite, responsible for causing malaria, is a protozoan with four identified species which causes human malaria via a female Anophelous mosquito as a vector, namely: $P$. falciparum, P.vivax, P. malariae and $P$. ovale ${ }^{2}$. Even though these four species of plasmodium parasite can infect human and cause malaria, $P$. falciparum is the most risky and potentially threatening ${ }^{8}$. However, Plasmodium vivax also creates significant human morbidity, suffering and economic loss, being responsible for 70 million to 80 million cases of the global malaria burden each year ${ }^{9}$.

\section{Epidemiology of malaria}

There are 109 malaria endemic countries in tropical and subtropical zones, across all countries except Antarctica and Australia. In these countries the intensities of transmission varies from very low to extremely high ${ }^{10}$. Human malaria infections caused an estimated 214 million clinical cases and 438,000 deaths in 2015. The relatively low case-fatality rate, even for the most virulent species, P. falciparum, is partly due to patient immunity acquired after repeated infections, but is also attributable to the timely provision of effective malaria drugs ${ }^{11}$. SSA region is the hardest hit by malaria comprising endemic areas of stable transmission ${ }^{12}$. The millennium development goal Target 8 "Global partnership for development” ("Have halted by 2015 and begin to reverse the incidence of malaria and other major diseases [including TB]") were to be met before 2015 13. Whereas, the target set under Millennium Development Goal 6 was to be reached by 55 countries that are on track to reduce their malaria burden by $75 \%$. Despite progress in the reduction of malaria morbidityand mortality in recent years, malaria remains one of the leading health problems in endemic countries ${ }^{14}$. Global malaria death estimates in the 1980s and 1990s range from 800000 to almost 2.5 million; in the 2000s, the range is from 650000 to more than 1 million. Studies showed that malaria is the underlying cause of death for 1.24 million 
individuals, including 714000 children younger than 5 years and 524000 individuals aged 5 years or older in $2010^{15}$. Children in sub-Saharan Africa and Southeast Asia have the highest risk of contracting and dying from malaria ${ }^{16}$. Being a curable disease, early diagnosis and prompt treatment is a key strategy to reduce morbidity and mortality from malaria. A core component of any malaria elimination program is to ensure that all patients with malaria are rapidly diagnosed, have access to highly effective antimalarial drugs ${ }^{14}$. Much of this morbidity and mortality could be avoided if drugs available to patients were efficacious, high quality, and used correctly ${ }^{16}$. During the past 5 years, substantial progress has been made in the fight against malaria, with a $31 \%$ reduction in global malaria deaths ${ }^{15}$.

\section{Life cycle of malaria}

Malaria parasites live in mosquito and human hosts and go through several developmental and transmission phases on the way to causing disease in humans ${ }^{17}$. Malaria is a mosquito-borne infectious disease transmitted by a parasitic protozoan in the Plasmodium genus ${ }^{18}$. The malaria parasite is a single-cell protozoan (plasmodium). Members of the genus Plasmodium have a complex life cycle, Figure 1. A sexual stage occurs within the Anopheles mosquito, while asexual stages take place in the host. Malaria is actually transmitted from one human to another through the insect vector, the female Anopheles mosquito ${ }^{19,20}$. Only the female mosquito bites because it needs blood to produce eggs. Mosquitoes bite a variety of hosts - birds, dogs, horses, cattle and people [18]. The infection of human erythrocytes is ultimately responsible for all the clinical pathologies associated with the disease ${ }^{17}$.

Initially, when female Anopheles mosquito bites an infected human, it gets infected and intakes gametocytes. The sexual transformation of gametocytes into ookinetes and ookinetes into oocyst takes place inside the midgut of mosquito. Finally, sporozoites are developed from oocysts, which eventually burst, releasing sporozoites into the salivary gland ${ }^{21}$. At the mosquito's next feeding, the sporozoites are injected into the blood stream of another human to begin the asexual stages. Once the mosquito inoculates the parasites (sporozoites) into the blood stream, the parasites invade the liver within $30 \mathrm{~min}$ and start replicating there (schizonts). In addition, $P$. vivax and $P$. ovale can remain dormant in the liver (hypnozoites, not shown in Figure 1) and cause relapses years after the initial infection ${ }^{22}$. After a relatively brief residence (less than an hour) in the systemic circulation, the sporozoites invade liver parenchymal cells, where they divide and develop asexually into multinucleated schizonts. These are the primary exoerythrocytic tissue forms of the parasite. When this primary stage of development is completed (6-12 days), the schizonts will rupture, releasing merozoites into the blood. These latter forms invade host erythrocytes, where they again grow and divide asexually (erythrocytic schizogony) and become red cell schizonts. Some of the parasites differentiate into sexual (male and female) forms, or gametocytes. If the diseased human is bitten by a mosquito at this time, the gametes will be taken up into the organism's gut to repeat the sexual cycle ${ }^{19}$. 


\section{Prevention and control of malaria}

Since the launch of the Roll Back Malaria initiative by WHO in 1998 and particularly in the past few years, malaria control has intensified in endemic countries, supported by a greatly increased investment of financial resources and technical assistance from the international community ${ }^{10}$. Three main strategies are presently attempting to control the disease: vaccination, vector control and parasiticidal drugs. Of these, parasiticidal drugs are currently the main line of disease control until vaccination or mosquito control can be implemented more successfully ${ }^{23}$. To eradicate malaria, achievable milestones must be set. The publication of the Global Malaria Action Plan (GMAP) by the WHO set some of those milestones; for example, a tenfold reduction in malaria incidence and deaths by 2030 (compared with 2015). The first GMAP was published in 2008 and covered the period until 2015. More recently, input and consultations are being sought from experts and regions for GMAP2. Both GMAP2 and the Global Technical Strategy for Malaria (co-ordinated by the WHO) will cover the 10 years between 2016 and $2025{ }^{24}$.On Oct 17, 2007, Bill and Melinda Gates called for complete eradication to be adopted as the new goal for the ageold fight against malaria, with the Director General of WHO, Margaret Chan, promptly echoing their conviction. Two crucial questions stand out for those organisations that will now begin striving towards malaria eradication. When and how can it be achieved? ${ }^{24,25}$.

During the past decade, a range of organizations have led a global movement to combat malaria. Accurate assessments of the levels and time trends in malaria burden are crucial for the assessment of progress towards goals and the focusing of future efforts ${ }^{15}$. A report released by WHO finds that the global burden of malaria remains enormous, but that access to malaria control interventions, especially bed nets in Africa, increased sharply between 2004 and $2006{ }^{26}$. As a result of malaria control efforts across the world, 80 countries are now in the phase of malaria control; 12 countries are making the program transition to elimination; 11 countries are operating malaria elimination programs; and 6 countries are actively engaged in preventing reintroduction of malaria ${ }^{10}$. Despite extensive control efforts, the incidence of the disease is not decreasing in most malaria-endemic areas of the world and in some it is clearly increasing ${ }^{27}$.

\section{Drugs for treatment of malaria}

Currently available antimalarial agents comprises classes of drugs classified based on their chemical structures and mechanism of action ${ }^{28}$. The number of antimalarial drugs in use today is limited due to the wide spread of resistance. Those in use to date are the quinine derivatives, the artemisinines and antifolate combination drugs. 


\subsection{Quinoline derivatives}

The quinoline derivatives have long been used for the treatment of malaria, the first one being quinine which is isolated from the bark extract of Cinchona trees. In $17^{\text {th }}$ century the pulverized bark was widely used in Europe. As the quest for new compounds for treating malaria was on rise the first 4(8)-aminoquinolines derivatives were deveolpped ${ }^{29}$. The success of the antimalarial aminoquinoline drugs has been based on excellent clinical efficacy, limited host toxicity, ease of use and simple, cost-effective synthesis ${ }^{30}$. The 4-aminoquinoline derivatives of quinine (1), shown in Figure 2, are chloroquine (2), amodiaquine (3) and mefloquine (4), whereas primaquine (5) is an 8-aminoquinoline derivative of quinine ${ }^{31}$. The mode of action and mechanism of resistance of these derivatives is not fully understood since much of the focus is directed to identification of novel chemotherapeutic agents ${ }^{32}$. The quinolines are known to inhibit the polymerization of heme and prevent disposal of polymers from the food vacuole to the cytoplasm where hemozoin is formed. This leads to intraparasitic accumulation of free-heme, which is highly toxic to the parasite ${ }^{33}$.

\subsection{Antifolate combination drugs}

Antifolates are various combinations of dihydrofolate-reductase inhibitors (proguanil (6), pyrimethamine (7), chlorproguanil (8) and trimethoprim (9)) and sulfa drugs (sulfadoxine (10), sulfamethoxazole (11), dapsone (12) and others), Figure 3. Most commonly used combinations include sulfadoxine-pyrimethamin and sulfamethoxazole-trimethoprim. Currently an antifolate combination drug, dapsone andchlorproguanil, was tested and has a more potent synergistic antimalarial action than other drugs such as sulfadoxine-pyrimethamine ${ }^{31}$.

\subsection{Antibiotics}

Tetracyclines (13 \& 14) Figure 4, usually in conjunction with quinine (1), have been reported to be suppressive in human malaria and proved to be of value as an additional drug for the radical cure of chloroquine-resistant falciparum infections. Clindamycin (15), alone or in combination with quinine, has also been used for the treatment of CQR falciparum malaria in Thiland with good results, despite the side effects. In non-immune individuals its efficacy has not been fully established ${ }^{34}$.

\subsection{Artemisinin compounds}

Artemisinin (qinghaosu) (16), artesunate (17), artemether (18) and arteether (19) have all been used alone or incombination therapy as antimalarial agents ${ }^{35}$. Artemisinin (16) Figure 5, which is present in the extracts of the aerial parts of the plant Artemissia annua, has been utilized for more than a millennia for fever and rediscovered as antimalarial agent ${ }^{36}$. Emergence of multidrug-resistant strains in P. falciparum and chloroquine -resistant strains of $P$. vivax in 
malaria endemic areas emphasize on preparing new, effective and affordable antimalarial medications. Thus, artemisinin combination therapy (ACT) was recommended by WHO for successful treatment of uncomplicated malaria ${ }^{37}$.

\subsection{Other compounds with antimalarial activity}

Halofantrine (20), which consists phenanthrene-methanol and illustrated in Figure 6, is a active against the erythrocytic stage of malaria. In areas of multi drug resistant falciparum malaria, halofantrine is mainly recommended. Atovaquone (21), which is a hydroxynaphtoquinone, is most widely used for treating opportunistic infections in immune-compromised patients. It is also effective against CQR P.falciparum, however its usually given in combination with proguanil to avoid the development of resistance. Lumefantrine (22), a fluoromethanol compound, is being produced as a fixed combination tablet with artemether [25] ${ }^{31}$.

\section{Antimalarial drug resistance}

Malaria continues to pose a challenge in view of its resurgence and problem of drug resistance. Chloroquine resistance in P. falciparum was first detected in Thailand in 1962 and in India in $1973^{38}$. Since 2000, malaria-associated mortality has been reduced by more than 50\%, but emerging drug- and insecticide-resistance continues to pose a major threat ${ }^{24}$. The efficacy of every antimalarial drug in use today has been jeopardized by the development drug resistance. In fact, the history of malarial drug developments parallels the history of drug resistance development $^{39}$. The WHO defined antimalarial drug resistance as the "ability of a parasite strain to survive and/or multiply despite the administration and absorption of a drug given in doses equal to or higher than those usually recommended but within tolerance of the subject." ${ }^{21}$. Broadly, there are two ways in which malaria parasites have become resistant to antimalarial drugs. Resistance against antifolates and atovaquone has arisen by mutations in drug targets that reduce their sensitivity; in these examples, an understanding of the molecular basis of drug action has been a prerequisite for elucidating the mechanism of drug resistance. Other drugs such as chloroquine and mefloquine may not have parasite-derived protein targets that can mutate, allowing parasites to escape from therapies. For these classes of antimalarial drugs, the parasite has become resistant through mutations in transporters involved in determining drug disposition within the intraerythrocytic parasite and its organelles. This effectively reduces drug concentrations at critical (presumed) target sites ${ }^{40}$.

The development of resistance to conventionally used anti-malarial drugs, such as chloroquine (CQ) and sulfadoxine-pyrimethamine (SP) has been documented ${ }^{14}$. Chloroquine resistance and high-level sulfadoxine-pyrimethamine resistance in $P$. falciparum both originated in South-East Asia and subsequently spread to Africa ${ }^{37}$. Currently scientists reported that, they have found the first evidence of resistance to the world's most effective drug coartem (lumefantrine and artemether) for treating malaria in western Cambodia ${ }^{31}$. Consequently, another change to 
artemether-lumefantrine was suggested in $2004^{41}$. WHO recommended that artemisinin-based combination therapy (ACT) should be used for treating uncomplicated Plasmodium falciparum malaria to ensure efficacy and reduce the emergence of drug-resistant parasites ${ }^{14,24}$. Several ACT combinations available include artemetherlumefantrine (AL), artesunate-amodiaquine (AS/AQ), artesunate-mefloquine (AS/MQ), artesunate-chlorproguanil-dapsone (AS/CD), artesunate-sulphadoxine-pyrimethamine (AS/SP), dihydroartemisinin-piperaquine (DA/PQ), artesunatepiperazine (AS/PZ), and artesunate-atovaquone-proguanil (A/AP). Out of these ACT combinations WHO recommended AL, AS/MQ, AS/AQ, and AS/SP. Several countries have now adopted ACTs as the first line agents for uncomplicated malaria ${ }^{42}$.

The concept of combination therapy relies on the rapid onset of schizonticidal action to rapidly reduce parasitaemia, leaving the residual parasitaemia to be cleared by high concentrations of the partner drug ${ }^{14}$. However, there is a constant threat of malaria evolving resistance to available drugs and recent observations that resistance may have arisen to the most widely used antimalarial drug class, the artemisinins ${ }^{11}$. Although ACTs are designed to reduce the chance of artemisinin drug resistance development, there are considerable concerns that this may already have occurred. For instance, there is now mounting evidence that the efficacy of artemisinin derivatives is reduced in Southeast Asia, where artemisinin derivatives have been used for a long time as monotherapies ${ }^{43}$.

The greatest challenge to malaria control and eradication is the emergence of malaria parasites that are resistant to antimalarial drugs ${ }^{21}$. The major drug resistance problem occurs with $P$. falciparum, which is of particular concern because of the enormous burden of disease caused by this species, its lethal potential, the propensity for epidemics and the cost of candidate replacement drugs for areas with established drug resistance [31] ${ }^{37}$. Whereas, other less lethal strains, P. ovale and P. vivax, can exist as latent hypnozoites in the liver which can initiate a relapse months to years after the initial infection ${ }^{44}$. Plasmodium falciparum can be clinically resistant to all monotherapy with current antimalarial drugs. In South-East Asia the combination of quinine and tetracycline is the treatment of choice for multidrug- resistant $P$. falciparum infections ${ }^{45}$.

Future drug candidates that are developed with the aim to circumvent or stall resistance will help produce the next generation of therapies that prevent or reduce mortality ${ }^{39}$. Any new antimalarial drug that is developed will ultimately be delivered as a combination therapy to delay the likely emergence of parasite resistance. Compounds in combinations should ideally act against different cellular targets to offset the likelihood that a single parasite genomeamplification event could render parasites resistant to both drugs ${ }^{46}$. Furthermore, poor-quality antimalarial drugs are very likely to jeopardize the unprecedented progress and investments in control and elimination of malaria made in the past decade. Of the many public health consequences of poor-quality antimalarial drugs, drug resistance is a particular concern. Low concentrations of active pharmaceutical ingredient in poor quality anti malarial drugs can result in sub-therapeutic concentrations of drug in vivo, which contributes to the selection of resistant 
parasites ${ }^{16}$. Thus, we need to protect the medicines we have by ensuring correct deployment and continual vigilance to stop the production and distribution of counterfeit medicines. Even with fixed-dose combinations there remains a risk of resistance emerging, and therefore a need for new medicines. New molecules should shorten the duration of treatment and increase compliance, and also prevent the transmission of the parasite back to the insect vector ${ }^{24}$. Therefore, there is an urgent need to gain information about the basic mechanisms through which antimalarial drugs act and resistance is generated in order not only to identify new targets and develop new drugs with novel mechanisms of action, but also to take advantage of the mode of action of available drugs and make better use of them ${ }^{47}$.

\section{Recent advances in antimalarial drug development}

Mefloquine is the only synthetic antimalrial agent discovered over the past 30 years. Whereas, artimisisin, which is discovered in this period is a natural product, whose medicinal actions have been known for over 2 millennia ${ }^{48}$. However the sudden resurgence of malaria and emergence of malarial drug resistancein many countries of the world have made the synthetic efforts toward new antimalarial drugs very important ${ }^{28}$. Recently some synthetic compounds are reported to have potent antimalarial activity against different Plasmodium species.

Clinical trials conducted with fosmidomycin (23) in combination with clindamycin (15) or artesunate (17) have shown high efficiency in the treatment of acute, uncomplicated malaria ${ }^{48}$. Recently synthetic chalcone analogue, 2,4-dimethoxy-4'butoxychalcone (24), was reported to have outstanding antimalarial activity ${ }^{49,50}$. In addition to this, the antimalarial activity of naphthoquinone derivatives (25), Figure 7, has been widely reported. Acylation of the hydroxy moiety of atovaquone (21) led to a compound exhibiting similar activity as atovaquone (21) and more active than chloroquine (2) and quinine (1) against P. falciparum ${ }^{51}$. Arylsulfonyl acridinyl derivatives (26), having acridinic ring and arylsulfone moiety together, are also reported to have an antimalarial activity on P. falciparum ${ }^{52}$.

Structure-based drug design resulted in P218 (28), a DHFR inhibitor active against all clinically relevant mutations. P218 (28) combines the pyrimidine ring of pyrimethamine (Figure 8), which brings potency, and the linker of the DHFR inhibitor WR99210 (27), which tolerates mutations due to its flexibility. P218 is more potent than pyrimeth amine against DHFR in the wild-type strain TM4 (IC50= 4.6 and $58 \mathrm{nM}$, respectively) as well as in the quadruple mutant strain V1/S (IC50 $=56$ and $>100,000 \mathrm{nM}$, respectively) ${ }^{22}$.

Recently, a series of bisquinolines (29, 30, 31, 32 and 33, Figure 9), where the 4-aminoquinoline part of chloroquine was retained and the two units were joined by bisamide links, have been synthesized and screened against CQS and CQR strains of $P$. falciparum in vitro. The resistant indices for all the compounds were found to be lower than that of CQ. The position of attachment and length of the linker chain had marked effect on the activity ${ }^{33}$. 


\section{Plasmepsins: Potential Drug Targets for Antimalarial Drugs}

With the technological developments of the past few decades, the ability to search for new drug candidates has rapidly accelerated. Advances in robotic automation and liquid handling, coupled with the ever-shrinking scale at which these assays are performed, have facilitated ultra-HTS of very large compound libraries ${ }^{46}$. Identification of novel drug targets and design of new chemical compounds acting on new targets is nowadays widely used approach all over the world to combat issue raised by emergence of resistance to existing drugs. Therefore, investigating inhibitors specific for the new target proteins of malaria parasite has been exploited for drug target identification and currently studies are underway ${ }^{53}$. Thus far, the genetics underlying the emergent resistance against artemisinins are becoming increasingly understood, and this knowledge is being used to set up panels of parasites against which new drug candidates can be tested ${ }^{54}$. Detecting the novel genetic basis for malaria not only reveals the disease pathogenesis, but also facilitates discovering new targets for anti-malaria drugs ${ }^{55}$. There is an argument to be made that hitting the sexual stages is useful- this blocks transmission and may delay resistance since there are several orders of magnitude fewer parasites from which to select mutants ${ }^{56}$. Given that the liver stage would be highly desirable for candidate drugs to have activity against hepatic and sexual forms of the malarial parasite, it is surprising that few clinical trials, to date, have examined whether gametocyte carriage can be reduced following drug treatment ${ }^{57}$.

Because proteases play important roles during parasite infection of and development in the mosquito, they were considered as potential transmission-blocking targets. Transcriptomic data suggested that Plasmodium aspartic proteases, known as plasmepsins, are expressed in sexual stage parasites ${ }^{58}$. There are 10 plasmepsins in $\mathrm{P}$. falciparum. Other Plasmodium species have only seven; they have only one digestive vacuole plasmepsin instead of the four in falciparum ${ }^{56}$. Plms I-IV are the most studied isoforms owing to their expression and important role during the blood stage. Whereas Plm II still remains the best studied isozyme, Plms V-X remain considerably less understood; recent studies show that Plm V functions as Plasmodium export element (PEXEL)-cleaving protease for protein export from the food vacuole to the erythrocyte to enable the development of P. falciparumparasites ${ }^{59,60}$. Expression of Plm I, II, IV, V, IX, X, and HAP occurs in the erythrocytic stage, whereas Plm VI, VII, and VIII are expressed in the exo-erythrocytic stages. The digestive vacuole plasmepsins are $55-75 \%$ identical to each other but $10-25 \%$ identical to the other plasmepsins ${ }^{61}$. It has been shown that the general aspartic proteinase inhibitor isovaleryl pepstatin is a tight binding (sub-nanomolar $\mathrm{K}_{\mathrm{i}}$ ) inhibitor of plasmepsin I and plasmepsin II. However, this compound inhibits most aspartic proteinases and so has no value as a potential drug ${ }^{62}$. Plasmepsin $\mathrm{V}$ is an aspartic acid protease expressed by protozoan parasites of Plasmodium species, and it has a crucial role in recognizing and processing effector proteins for export to host cells. The most potent plasmepsin V inhibitor to date, WEHI-916 (34), has a high affinity for the endogenous enzyme but has a modest ability to inhibit P. falciparum growth ${ }^{63}$. Other small nonpeptide inhibitors of Plm II 
based on a diphenylurea unit were discovered by screening of compounds in the Walter Reed chemical database. BothP. Falciparum Plm II and P. Vivax plasmepsin were used in the screening assays. Compounds $\mathbf{3 5}$ and 36, Figure 10, were identified as the lead inhibitors with important high-plasmepsin potency ${ }^{61}$.

\section{Review of quinazolinones}

Various structural class of compounds have been reported to posses antimalarial activities such as chalcones ${ }^{51}$, thienopyrimidinone ${ }^{64}$, quinolones, quinazolins ${ }^{47}$, enaminones ${ }^{65}$, acridines ${ }^{48}$. Among the different heterocyclic structures which have been studied for their antiplasmodial properties, quinazoline has quite recently showed increasing interest ${ }^{66}$. Quinazolinones are versatile nitrogen heterocyclic compounds, displaying wide applications including anticonvulsant, sedative, tranquilizer, analgesic, antimicrobial ${ }^{67}$, anesthetic, antioxidant ${ }^{68}$, anticancer, antiviral ${ }^{67}$, anti-TB ${ }^{69}$, antihypertensive, anti-inflammatory, antimalarial, diuretic and muscle relaxant properties, Table1. Increased efforts in antimalarial drug discovery are urgent to develop safe and affordable new drugs to counter the spread of malaria parasites that are resistant to existing agents. Furthermore, quinazolinones substituted at 2 and 3-position play a pivotal

role in the antimalarial activity ${ }^{70-72}$. Moreover, there are marketed quinazoline derivatives such as prazocin and trazocin as antihypertensive agents ${ }^{67,73}$ and Gentifib as anticancer ${ }^{73}$ and alfuzosin for treating benign prostatic hyperplasia, which gives hope to research in classes of compounds ${ }^{73}$.

\section{Febrifugines derivatives and other important quinazolinones}

The isomeric alkaloids (+)-febrifugine (51) and (+)-isofebrifugine (52), Figure 11, are found in the roots and leaves of the Chinese medicinal plant Dichroa febrifuga (also called Chinese quinine) belonging to the Saxifragaceae family[83]. Several bio-active natural products such as febrifugine (51) and isofebrifugine (52) contain quinazolinone moieties with potential antimalarial activity ${ }^{83}$. Compound 53 with an extra nitrogen atom on the position 5 or 6 of the aromatic ring $(\mathrm{IC} 50=1.2 \mathrm{nM})$ possessed antimalarial activity comparable to $\mathbf{5 1}$, while compound 54 (IC50 = $0.33 \mathrm{nM}$ ) with difluoride attached to C-5 and C-6 was superior to febrifugine. These compounds were 100 times less toxic than febrifugine ${ }^{84}$. In one study it was reported that antimalarial activity of a series of febrifugine derivatives bearing structural modifications at: (i) the quinazoline ring, (ii) the linker, or (iii) the piperidine ring. Thienopyrimidine analog 55 exhibited potent antimalarial activity and a high therapeutic selectivity both in vitro and in vivo $\left[\mathrm{EC} 50=0.00306 \mathrm{lg} / \mathrm{mL}\right.$ (P. falciparum FCR-3), $\mathrm{ED}_{50}=2.95 \mathrm{mg} / \mathrm{kg}, \mathrm{LD}_{50}=88 \mathrm{mg} / \mathrm{kg}(P$. berghei) ${ }^{85}$. The fluorinated analogue 57 , which was designed to prevent metabolic oxidation, actually showed higher antimalarial activity than that of (+)-febrifugine (51) but it also proved more toxic. On the other hand analogue 55 showed high in vitro and in vivo antimalarial activity however, the other analogues, 57-59, showed little antimalarial activity with total loss of antimalarial activity being observed for 60. The complete loss of antimalarial activity in 
analogue $\mathbf{6 0}$ clearly indicates that a basic nitrogen group within the heteroaromatic portion is essential for antimalarial activity ${ }^{85-87}$. Febrifugine acts by impairing haemazoin formation required for maturation of the parasite at the trophozoite stage. The use of febrifugine as antimalarial agent is initially appealing not only because of its rapid effect and no drug resistance, but also because of its availability. Subsequent pre-clinical researches have found that febrifugine possesses adverse side effects. Strong liver toxicity has precluded febrifugine as a clinical drug ${ }^{22,69,88}$. There are some marketed available drugs possessing quinazoline and quinazolinone ring such as the antisolid tumor Nolatrexed (61), Sotrastaurin (62) used for psoriasis and ulcerative colitis, Tandutinib (63) for gloiblastoma, Varlitinib (64) for anticancer and Elinogrel (65) as antithrombosis ${ }^{70}$.

\section{CONCLUSION}

Globally the importance fighting malaria is recognized, however the burden of malaria is still high in developing countries especially in the Sub-Saharan African region. Although decades long efforts and accadamic engagements has been there malaria continues to pose challenge in view of its resurgence and problem of drug resistance. Most of the existing antimalarial drugs including chloroquine are brought to the side line by the emergence of resistance. Currently a combination therapy is recommended by WHO to reduce the risk of drug resistance. However, there are still reports indicating drug resistance even to those used in combination recommended by WHO such as artimisinin. Thus, malaria drug discovery is unquestionably urgent to battle against the disease. To minimize the likely hood of cross resistance the focus of the drug discovery must be on newer drug targets, such as plasmepsin. In finding a novel antimalarial agent various library of chemicals has been investigated and hetrocyclic compounds such as chalcones, thienopyrimidinone, quinolones, quinazolins, quinazolinones, enaminones, and acridines have been reported to posses antimalarial activity. Further, assessment on quinazolinones has showed fruitful results and their activity as antimalarial agent is appealing. In this regard, febrifugine and its derivatives have been reported to have excellent activity. Therefore, quinazolinones can be considered potential compounds in seeking for novel drugs that act against the malarial pathogen.

\section{Acknowledgements}

All the authors of the manuscript thank and acknowledge their respective Universities and Institutes.

\section{Conflict of Interest}

The authors declare that they have no conflict of interest.

\section{Authors' Contribution}


MHB, FM and IA collected literatures and drafted the paper. KD, and HMNI participated in the manuscript preparation, drafted the manuscript. Moreover, MHB, FM, IA, KD and HMNI reviewed and performed the final check. All the authors read and approved the final manuscript.

\section{Orcid}

\section{Mohammed Hussen Bule}

http:// orcid.org/0000-0002-1040-1583

\section{Kuldeep Dhama}

http://orcid.org/0000-0001-7469-4752

https://livedna.net/?dna=91.4710

\section{References}

1. de Oliveira RB., de Souza-Fagundes EM., Soares RPP., Andrade AA., Krettli AU., Zani CL, 2008. Synthesis and antimalarial activity of semicarbazone and thiosemicarbazone derivatives. Eur J Med Chem., 43:1983-8. https://doi.org/10.1016/j.ejmech.2007.11.012.

2. Kalra BS., Chawla S., Gupta P., Valecha N, 2006. Screening of antimalarial drugs: An overview. Indian J Pharmacol., 38:5. https://doi.org/10.4103/0253-7613.19846.

3. World Economic Forum. Global Health Initiative, Harvard School of Public Health Business and malaria: a neglected threat? Geneva, Switzerland: World Economic Forum, Global Health Initiative in cooperation with Harvard School of Public Health; 2006. Available from: http://allafrica.com/download/resource/main/main/idatcs/00011012:690add3c64834fd5e 266b865e6784c52.pdf. [Accessed 26 February 2017].

4. Bule MH., Haymete A., Kefale B, 2015. Synthesis and In-Vivo Pharmacological Evaluation of Some Novel 4(3H)- Quinazolinone Derivatives as Potential Anti-malarial Agents. Drug Des Open Access. https://doi.org/10.4172/2169-0138.1000121.

5. pmi_annual_report09.pdf. n.d. Available from: https://www.pmi.gov/docs/defaultsource/default-document-library/pmi-reports/pmi_annual_report09.pdf?sfvrsn=13. [Accessed 27 February 2017].

6. Diagana TT, 2015. Supporting malaria elimination with 21st century antimalarial agent drug discovery. Drug Discov Today, 20:1265-70.

https://doi.org/10.1016/j.drudis.2015.06.009. 
7. WHO | World Health Statistics 2006. WHO. Available from:

http://www.who.int/whosis/whostat2006/en/. [Accessed 28 February 2017].

8. Dikasso D., Makonnen E., Debella A., Abebe D., Urga K., Makonnen W., 2006. In vivo antimalarial activity of hydroalcoholic extracts from Asparagus africanus Lam. in mice infected with Plasmodium berghei. EthiopJHealth Dev, 20:112-8.

9. Mbatchi SF., Mbatchi B., Banzouzi JT., Bansimba T., Nsonde Ntandou GF., Ouamba J-M., et al, 2006. In vitro antiplasmodial activity of 18 plants used in Congo Brazzaville traditional medicine. J Ethnopharmacol., 104:168-74. https://doi.org/10.1016/j.jep.2005.08.068.

10. WHO | Malaria. WHO. Available from: http://www.who.int/malaria/en/.[ Accessed 28 February 2017].

11. Hastings IM., Hodel EM., Kay K, 2016. Quantifying the pharmacology of antimalarial drug combination therapy. Sci Rep., 6:32762. https://doi.org/10.1038/srep32762.

12. WHO | World Health Statistics 2005. WHO. Available from: http://www.who.int/whosis/whostat/2005/en/. [Accessed 28 February 2017].

13. WHO | World Health Statistics 2007. WHO. Available from: http://www.who.int/whosis/whostat2007/en/. [Accessed 28 February, 2017].

14. Naing C., Whittaker MA., Mak JW., Aung K, 2015. A systematic review of the efficacy of a single dose artemisinin-naphthoquine in treating uncomplicated malaria. Malar. J., 14:392. https://doi.org/10.1186/s12936-015-0919-5.

15. Murray CJ., Rosenfeld LC., Lim SS., Andrews KG., Foreman KJ., Haring D., et al, 2012. Global malaria mortality between 1980 and 2010: a systematic analysis. The Lancet., 379:413-31. https://doi.org/10.1016/S0140-6736(12)60034-8.

16. Nayyar GM., Breman JG., Newton PN., Herrington J, 2012. Poor-quality antimalarial drugs in southeast Asia and sub-Saharan Africa. Lancet Infect. Dis., 12:488-96. https://doi.org/10.1016/S1473-3099(12)70064-6.

17. Haldar K., Murphy SC., Milner DA., Taylor TE, 2007. Malaria: mechanisms of erythrocytic infection and pathological correlates of severe disease. Annu. Rev. Pathol., 2:217-49. https://doi.org/10.1146/annurev.pathol.2.010506.091913.

18. Muanda FT., Chaabane S., Boukhris T., Santos F., Sheehy O., Perreault S., et al, 2015. Antimalarial drugs for preventing malaria during pregnancy and the risk of low birth 
weight: a systematic review and meta-analysis of randomized and quasi-randomized trials. BMC Med., 13:193. https://doi.org/10.1186/s12916-015-0429-x.

19. Charles R. C., Robert E. S, 2003. Modern Pharmacology With Clinical Applications, Sixth Edition. Philadelphia: LWW.

20. Pérez-Tris J., Hasselquist D., Hellgren O., Krizanauskiene A., Waldenström J., Bensch S, 2005. What are malaria parasites? Trends Parasitol., 21:209-11. https://doi.org/10.1016/j.pt.2005.03.001.

21. Sharma C. and Kumar A., 2015. Recent Advances in Antimalarial Drug Discovery Challenges and Opportunities, An Overview of Tropical Diseases, Amidou S. (Ed.), INTECH Open Acsess Publisher, pp: 2829-2843.

22. Biamonte MA., Wanner J., Le Roch KG, 2013. Recent advances in malaria drug discovery. Bioorg Med. Chem. Lett., 23:2829-43. https://doi.org/10.1016/j.bmcl.2013.03.067.

23. Ralph SA., D’Ombrain MC., McFadden GI, 2001. The apicoplast as an antimalarial drug target. Drug Resist Update Rev. Comment. Antimicrob. Anticancer Chemother., 4:14551. https://doi.org/10.1054/drup.2001.0205.

24. Wells TNC., van Huijsduijnen RH., Van Voorhis WC, 2015. Malaria medicines: a glass half full? Nat Rev Drug Discov, 14:424-42. https://doi.org/10.1038/nrd4573.

25. Feachem R., Sabot O, 2008. A new global malaria eradication strategy. The Lancet. 371:1633-5. https://doi.org/10.1016/S0140-6736(08)60424-9.

26. WHO | World Malaria Report. WHO. Available from: http://www.who.int/malaria/publications/world_malaria_report/en/. [Accessed 28 February 2017].

27. WHO | World Health Statistics 2008. WHO. Available from: http://www.who.int/whosis/whostat/2008/en/. [Accessed 28 February 2017].

28. Ballou WR., Arevalo-Herrera M., Carucci D., Richie TL., Corradin G., Diggs C., et al, 2004. Update on the clinical development of candidate malaria vaccines. Am J Trop Med Hyg, 71:239-47.

29. Rosenthal PJ, 1998. Proteases of malaria parasites: new targets for chemotherapy. Emerg Infect Dis, 4:49-57. https://doi.org/10.3201/eid0401.980107. 
30. Vangapandu S., Jain M., Kaur K., Patil P., Patel SR., Jain R, 2007. Recent advances in antimalarial drug development. Med Res Rev, 27:65-107. https://doi.org/10.1002/med.20062.

31. S D-C., E P., L M., E M., C S., P G., et al, 2008. Synthesis and antimalarial activity of new analogues of amodiaquine. Eur J Med Chem, 43:252-60, https://doi.org/10.1016/j.ejmech.2007.03.008.

32. Smith RD., Coast J, 2002. Antimicrobial resistance: a global response. Bull World Health Organ, 80:126-33. https://doi.org/10.1590/S0042-96862002000200008.

33. Kaur K., Jain M., Reddy RP., Jain R, 2010. Quinolines and structurally related heterocycles as antimalarials. Eur J Med Chem, 45:3245-64. https://doi.org/10.1016/j.ejmech.2010.04.011.

34. Vv K., A G-B, 2009. Recent developments in the design and synthesis of hybrid molecules based on aminoquinoline ring and their antiplasmodial evaluation. Eur J Med Chem, 44:3091-113. https://doi.org/10.1016/j.ejmech.2009.02.024.

35. WHO Expert Committee on Malaria (1998 : Geneva S., Organization WH. WHO Expert Committee on Malaria : twentieth report. Comité OMS d' experts du paludisme : vingtième rapport. 2000. Available from: http://apps.who.int/iris/handle/10665/42247. [Accessed 14 February 2017].

36. Malaria GP to RB. Antimalarial drug combination therapy : report of a WHO technical consultation, 4-5 April 2001. 2001. Available from: http://apps.who.int/iris/handle/10665/66952. [Accessed 28 February 2017].

37. Khodadad M., Nateghpour M., Sourie., Farivar L., Motevallihaghi A., Rahimi-Froushani A., et al, 2013. Evaluation of Effectiveness of Ethanolic Extract of Artemisia aucheri, Individually and in Combination with Chloroquine, on Chloroquine - Sensitive Strain of Plasmodium berghei in Sourian Mice. Iran J Public Health, 42:883-8.

38. N M., P A., B K., Lc M., A B., Sk A., et al, 2008. Synthesis of novel substituted 1,3-diaryl propenone derivatives and their antimalarial activity in vitro. Eur J Med Chem, 43:1530-5. https://doi.org/10.1016/j.ejmech.2007.09.014.

39. Buckner FS., Waters NC., Avery VM, 2012. Recent highlights in anti-protozoan drug development and resistance research. Int J Parasitol Drugs Drug Resist, 2:230-5. https://doi.org/10.1016/j.ijpddr.2012.05.002. 
40. Woodrow CJ., Krishna S, 2006. Antimalarial drugs: recent advances in molecular determinants of resistance and their clinical significance. Cell Mol Life Sci CMLS, 63:1586-96. https://doi.org/10.1007/s00018-006-6071-1.

41. WHO | Guidelines for the treatment of malaria. Third edition. WHO. Available from: http://www.who.int/malaria/publications/atoz/9789241549127/en/. [Accessed 14 February 2017].

42. Yakasai AM., Hamza M., Dalhat MM., Bello M., Gadanya MA., Yaqub ZM., et al, 2015. Adherence to Artemisinin-Based Combination Therapy for the Treatment of Uncomplicated Malaria: A Systematic Review and Meta-Analysis. J Trop Med, 189232. https://doi.org/10.1155/2015/189232.

43. Nzila A., Rottmann M., Chitnumsub P., Kiara SM., Kamchonwongpaisan S., Maneeruttanarungroj C., et al, 2010. Preclinical Evaluation of the Antifolate QN254, 5Chloro- N'6'-(2,5-Dimethoxy-Benzyl)-Quinazoline-2,4,6-Triamine, as an Antimalarial Drug Candidate. Antimicrob Agents Chemother, 54:2603-10. https://doi.org/10.1128/AAC.01526-09.

44. Ezenyi IC., Salawu OA, 2016. Approaches, Challenges and Prospects of Antimalarial Drug Discovery from Plant Sources, Alfonso R.M.(Ed.), INTECH Open Access Publisher, pp: 187-204.

45. Schunk M., Kumma WP., Miranda IB., Osman ME., Roewer S., Alano A., et al, 2006. High prevalence of drug-resistance mutations in Plasmodium falciparum and Plasmodium vivax in southern Ethiopia. Malar J., 5:54. https://doi.org/10.1186/1475-2875-5-54.

46. Hovlid ML., Winzeler EA, 2016. Phenotypic Screens in Antimalarial Drug Discovery. Trends Parasitol, 32:697-707. https://doi.org/10.1016/j.pt.2016.04.014.

47. Rojas-Aguirre Y., Hernández-Luis F., Mendoza-Martínez C., Sotomayor CP., Aguilar LF., Villena F., et al, 2012. Effects of an antimalarial quinazoline derivative on human erythrocytes and on cell membrane molecular models. Biochim Biophys Acta BBA Biomembr, 1818:738-46. https://doi.org/10.1016/j.bbamem.2011.11.026.

48. Loiseau PM., Nguyen DX, 1996. Plasmodium berghei mouse model: antimalarial activity of new alkaloid salts and of thiosemicarbazone and acridine derivatives. Trop Med Int Health TM IH, 1:379-84.

49. Schlüter K., Walter RD., Bergmann B., Kurz T, 2006. Arylmethyl substituted derivatives of Fosmidomycin: synthesis and antimalarial activity. Eur J Med Chem, 41:1385-97. https://doi.org/10.1016/j.ejmech.2006.06.015. 
50. Xue CX., Cui SY., Liu MC., Hu ZD., Fan BT, 2004. 3D QSAR studies on antimalarial alkoxylated and hydroxylated chalcones by CoMFA and CoMSIA. Eur J Med Chem, 39:745-53. https://doi.org/10.1016/j.ejmech.2004.05.009.

51. Valla A., Valla B., Cartier D., Le Guillou R., Labia R., Florent L., et al, 2006. New syntheses and potential antimalarial activities of new "retinoid-like chalcones.” Eur J Med Chem, 41:142-6. https://doi.org/10.1016/j.ejmech.2005.05.008.

52. El Hage S., Ane M., Stigliani J-L., Marjorie M., Vial H., Baziard-Mouysset G., et al, 2009. Synthesis and antimalarial activity of new atovaquone derivatives. Eur J Med Chem, 44:4778-82. https://doi.org/10.1016/j.ejmech.2009.07.021.

53. Nigussie D., Beyene T., Shah NA., Belew S, 2015. New Targets in Malaria Parasite Chemotherapy: A Review. Malar Control Elimin,1-6. https://doi.org/10.4172/24706965.1000S1-007.

54. Katsuno K., Burrows JN., Duncan K., van Huijsduijnen RH., Kaneko T., Kita K., et al, 2015. Hit and lead criteria in drug discovery for infectious diseases of the developing world. Nat Rev Drug Discov, 14:751-8. https://doi.org/10.1038/nrd4683.

55. Chen Y., Xu R, 2015. Network-based gene prediction for Plasmodium falciparum malaria towards genetics-based drug discovery. BMC Genomics, 16:S9. https://doi.org/10.1186/1471-2164-16-S7-S9.

56. J. Meyers M., E. Goldberg D, 2012. Recent Advances in Plasmepsin Medicinal Chemistry and Implications for Future Antimalarial Drug Discovery Efforts. Curr Top Med Chem, 12:445-55. https://doi.org/10.2174/156802612799362959.

57. Delves M., Plouffe D., Scheurer C., Meister S., Wittlin S., Winzeler EA., et al, 2012. The Activities of Current Antimalarial Drugs on the Life Cycle Stages of Plasmodium: A Comparative Study with Human and Rodent Parasites. PLOS Med, 9:e1001169. https://doi.org/10.1371/journal.pmed.1001169.

58. Li F., Bounkeua V., Pettersen K., Vinetz JM, 2016. Plasmodium falciparum ookinete expression of plasmepsin VII and plasmepsin X. Malar J, 15:111. https://doi.org/10.1186/s12936-016-1161-5.

59. Huizing AP., Mondal M., Hirsch AKH, 2015. Fighting Malaria: Structure-Guided Discovery of Nonpeptidomimetic Plasmepsin Inhibitors. J Med Chem, 58:5151-63. https://doi.org/10.1021/jm5014133.

60. Gambini L., Rizzi L., Pedretti A., Taglialatela-Scafati O., Carucci M., Pancotti A., et al, 2015. Picomolar Inhibition of Plasmepsin V, an Essential Malaria Protease, Achieved 
Exploiting the Prime Region. PLOS ONE, 10:e0142509.

https://doi.org/10.1371/journal.pone.0142509.

61. Ersmark K., Samuelsson B., Hallberg A, 2006. Plasmepsins as potential targets for new antimalarial therapy. Med Res Rev, 26:626-66. https://doi.org/10.1002/med.20082.

62. Berry C, 1997. New targets for antimalarial therapy: The plasmepsins, malaria parasite aspartic proteinases. Biochem Educ, 25:191-4. https://doi.org/10.1016/S03074412(97)00130-1.

63. Hodder AN., Sleebs BE., Czabotar PE., Gazdik M., Xu Y., O’Neill MT., et al, 2015. Structural basis for plasmepsin $\mathrm{V}$ inhibition that blocks export of malaria proteins to human erythrocytes. Nat Struct Mol Biol, 22:590-6. https://doi.org/10.1038/nsmb.3061.

64. Sun Y., Wu J., Wan J., Ding M-W, 2009. Efficient synthesis and fungicidal activities of 2alkylamino-6-(1H-1,2,4-triazol-1-yl)-thieno[2,3-d]pyrimidin-4(3H)-ones. Arch Org Chem Volume 2009:111-8. https://doi.org/http://dx.doi.org/10.3998/ark.5550190.0010.711.

65. Edafiogho IO., Qaddoumi MG., Ananthalakshmi KVV., Phillips OA., Kombian SB, 2014. Synthesis, neuronal activity and mechanisms of action of halogenated enaminones. Eur J Med Chem, 76:20-30. https://doi.org/10.1016/j.ejmech.2014.02.002.

66. Kabri Y., Azas N., Dumètre A., Hutter S., Laget M., Verhaeghe P., et al, 2010. Original quinazoline derivatives displaying antiplasmodial properties. Eur J Med Chem, 45:61622. https://doi.org/10.1016/j.ejmech.2009.11.005.

67. Jafari E., Khajouei MR., Hassanzadeh F., Hakimelahi GH., Khodarahmi GA, 2016. Quinazolinone and quinazoline derivatives: recent structures with potent antimicrobial and cytotoxic activities. Res Pharm Sci, 11:1-14.

68. Sutherland JB., Heinze TM., Schnackenberg LK., Freeman JP., Williams AJ, 2011. Biotransformation of quinazoline and phthalazine by Aspergillus niger. J Biosci Bioeng, 111:333-5. https://doi.org/10.1016/j.jbiosc.2010.11.017.

69. C. Sharma P., Kaur G., Pahwa R., Sharma A., Rajak H, 2011. Quinazolinone Analogs as Potential Therapeutic Agents. Curr Med Chem, 18:4786-812. https://doi.org/10.2174/092986711797535326.

70. Asif M, 2014. Chemical Characteristics, Synthetic Methods, and Biological Potential of Quinazoline and Quinazolinone Derivatives. Int J Med Chem, Volume 2014:1-27. https://doi.org/10.1155/2014/395637. 
71. Maarouf AR., El-Bendary ER., Goda FE, 2004. Synthesis and evaluation of some novel quinazolinone derivatives as diuretic agents. Arch Pharm (Weinheim), 337:527-32. https://doi.org/10.1002/ardp.200400869.

72. Sharma M., Pandey S., Chauhan K., Sharma D., Kumar B., Chauhan PMS, 2012. Cyanuric Chloride Catalyzed Mild Protocol for Synthesis of Biologically Active Dihydro/Spiro Quinazolinones and Quinazolinone-glycoconjugates. J Org Chem, 77:929-37. https://doi.org/10.1021/jo2020856.

73. Selvam TP., Kumar PV, 2011. Quinazoline Marketed drugs. Res Pharm, 1: 1-21. Available from: http://scienceflora.org/journals/index.php/rip/article/view/204. [Accessed 14 February 2017]

74. Santelli-Rouvier C., Pradines B., Berthelot M., Parzy D., Barbe J, 2004. Arylsulfonyl acridinyl derivatives acting on Plasmodium falciparum. Eur J Med Chem, 39:735-44. https://doi.org/10.1016/j.ejmech.2004.05.007.

75. Alafeefy AM., Kadi AA., El-Azab AS., Abdel-Hamide SG., Daba M-HY, 2008. Synthesis, Analgesic and Anti-Inflammatory Evaluation of Some New 3H-Quinazolin-4-one Derivatives. Arch Pharm (Weinheim), 341:377-85. https://doi.org/10.1002/ardp.200700271.

76. Bhattacharjee AK., Hartell MG., Nichols DA., Hicks RP., Stanton B., van Hamont JE., et al, 2004. Structure-activity relationship study of antimalarial indolo [2,1-b]quinazoline6,12-diones (tryptanthrins). Three dimensional pharmacophore modeling and identification of new antimalarial candidates. Eur J Med Chem, 39:59-67. https://doi.org/10.1016/j.ejmech.2003.10.004.

77. Galli U., Lazzarato L., Bertinaria M., Sorba G., Gasco A., Parapini S., et al, 2005. Synthesis and antimalarial activities of some furoxan sulfones and related furazans. Eur J Med Chem, 40:1335-40. https://doi.org/10.1016/j.ejmech.2005.05.001.

78. Pandey SK., Singh A., Singh A., Nizamuddin N., 2009. Antimicrobial studies of some novel quinazolinones fused with [1,2,4]-triazole, [1,2,4]-triazine and [1,2,4,5]-tetrazine rings. Eur J Med Chem, 44:1188-97. https://doi.org/10.1016/j.ejmech.2008.05.033.

79. Grover G., Kini SG, 2006. Synthesis and evaluation of new quinazolone derivatives of nalidixic acid as potential antibacterial and antifungal agents. Eur J Med Chem, 41:25662. https://doi.org/10.1016/j.ejmech.2005.09.002.

80. Jatav V., Mishra P., Kashaw S., Stables JP, 2008. CNS depressant and anticonvulsant activities of some novel 3-[5-substituted 1,3,4-thiadiazole-2-yl]-2-styryl quinazoline- 
4(3H)-ones. Eur J Med Chem, 43:1945-54.

https://doi.org/10.1016/j.ejmech.2007.12.003.

81. Al-Obaid AM., Abdel-Hamide SG., El-Kashef HA., Abdel-Aziz AA-M., El-Azab AS., AlKhamees HA., et al, 2009. Substituted quinazolines, part 3. Synthesis, in vitro antitumor activity and molecular modeling study of certain 2-thieno-4(3H)-quinazolinone analogs. Eur J Med Chem, 44:2379-91. https://doi.org/10.1016/j.ejmech.2008.09.015.

82. Giri RS., Thaker HM., Giordano T., Williams J., Rogers D., Sudersanam V., et al, 2009. Design, synthesis and characterization of novel 2-(2,4-disubstituted-thiazole-5-yl)-3aryl-3H-quinazoline-4-one derivatives as inhibitors of NF-kappaB and AP-1 mediated transcription activation and as potential anti-inflammatory agents. Eur J Med Chem, 44:2184-9. https://doi.org/10.1016/j.ejmech.2008.10.031.

83. Kumar V., Mahajan A., Chibale K, 2009. Synthetic medicinal chemistry of selected antimalarial natural products. Bioorg Med Chem, 17:2236-75.

https://doi.org/10.1016/j.bmc.2008.10.072.

84. Kaur K., Jain M., Kaur T., Jain R, 2009. Antimalarials from nature. Bioorg Med Chem, 17:3229-56. https://doi.org/10.1016/j.bmc.2009.02.050.

85. Jain V., Yogavel M., Oshima Y., Kikuchi H., Touquet B., Hakimi M-A., et al, 2015. Structure of Prolyl-tRNA Synthetase-Halofuginone Complex Provides Basis for Development of Drugs against Malaria and Toxoplasmosis. Structure, 23:819-29. https://doi.org/10.1016/j.str.2015.02.011.

86. Kikuchi H., Horoiwa S., Kasahara R., Hariguchi N., Matsumoto M., Oshima Y, 2014. Synthesis of febrifugine derivatives and development of an effective and safe tetrahydroquinazoline-type antimalarial. Eur J Med Chem, 76:10-9. https://doi.org/10.1016/j.ejmech.2014.01.036.

87. McLaughlin NP., Evans P., Pines M, 2014. The chemistry and biology of febrifugine and halofuginone. Bioorg Med Chem, 22:1993-2004. https://doi.org/10.1016/j.bmc.2014.02.040.

88. Zhu S., Chandrashekar G., Meng L., Robinson K., Chatterji D, 2012. Febrifugine analogue compounds: Synthesis and antimalarial evaluation. Bioorg Med Chem, 20:927-32. https://doi.org/10.1016/j.bmc.2011.11.053. 
Table 1: Some 4 (3H)-quinazolinone derivatives and their biological activity

4 (3H)-quinazolinone derivatives<smiles>O=C1c2nc3ccccc3c(=O)n2C2C=CC=CC12</smiles>

37<smiles>Cc1ccc2nc(N)[nH]c(=O)c2c1Sc1ccncc1</smiles>

38

\section{Biological Activity ${ }^{\text {Ref. }}$}

(37) Antimalarial agents ${ }^{74}$

(38) Anticancer agents ${ }^{75}$<smiles>O=C(c1ccc(F)cc1)C1CCN(CCn2c(=O)[nH]c3ccccc3c2=O)CC1</smiles><smiles>O=c1c2ccc(Cl)cc2nc(/C=C/c2ccccc2)n1-c1nncs1</smiles>

(39) 5-HT, receptor antagonist ${ }^{76}$

(40) Diuretic ${ }^{77}$

39<smiles>O=c1c2ccccc2n2c(-c3ccccc3)nnc2n1-c1ccccc1</smiles><smiles>CCOc1cn(CC)c2c(c1=O)=CCC(C)N=2</smiles>

(41) Antimicrobial ${ }^{71}$

(42) Antibacterial and antifungal agents ${ }^{78}$

CNS depressant \&<smiles>Cc1ccccc1-c1nnc(-n2c(CCc3ccccc3)nc3ccccc3c2=O)s1</smiles><smiles>Cc1nc2n(C)c3ccc(I)cc3c(=O)n2n1</smiles>
anticonvulsant ${ }^{79}$

(44) Antihypertensive ${ }^{80}$<smiles></smiles><smiles>CC(c1nnc(S)n1N)n1c(-c2ccc(Cl)cc2)nc2ccc(I)cc2c1=O</smiles>

(45) Antimitotic agents ${ }^{81}$

Analgesic and AntiInflammatory ${ }^{82}$ 
<smiles>COc1cc2nc(N3CCN(C(=O)c4ccoc4)CC3)nc(N)c2cc1OC</smiles>

47<smiles>COc1cc2ncnc(Nc3ccc(F)c(C)c3)c2cc1OCCCN1CCOCC1</smiles>

49
(47), (48) Antihypertensive ${ }^{67,73}$<smiles>COc1cc2nc(N3CCN(C(=O)C4CCOC4)CC3)nc(N)c2cc1OC</smiles>

(49) Anticancer ${ }^{73}$

(50) Benign prostatic hyperplasia $(\mathrm{BPH})^{73}$ 


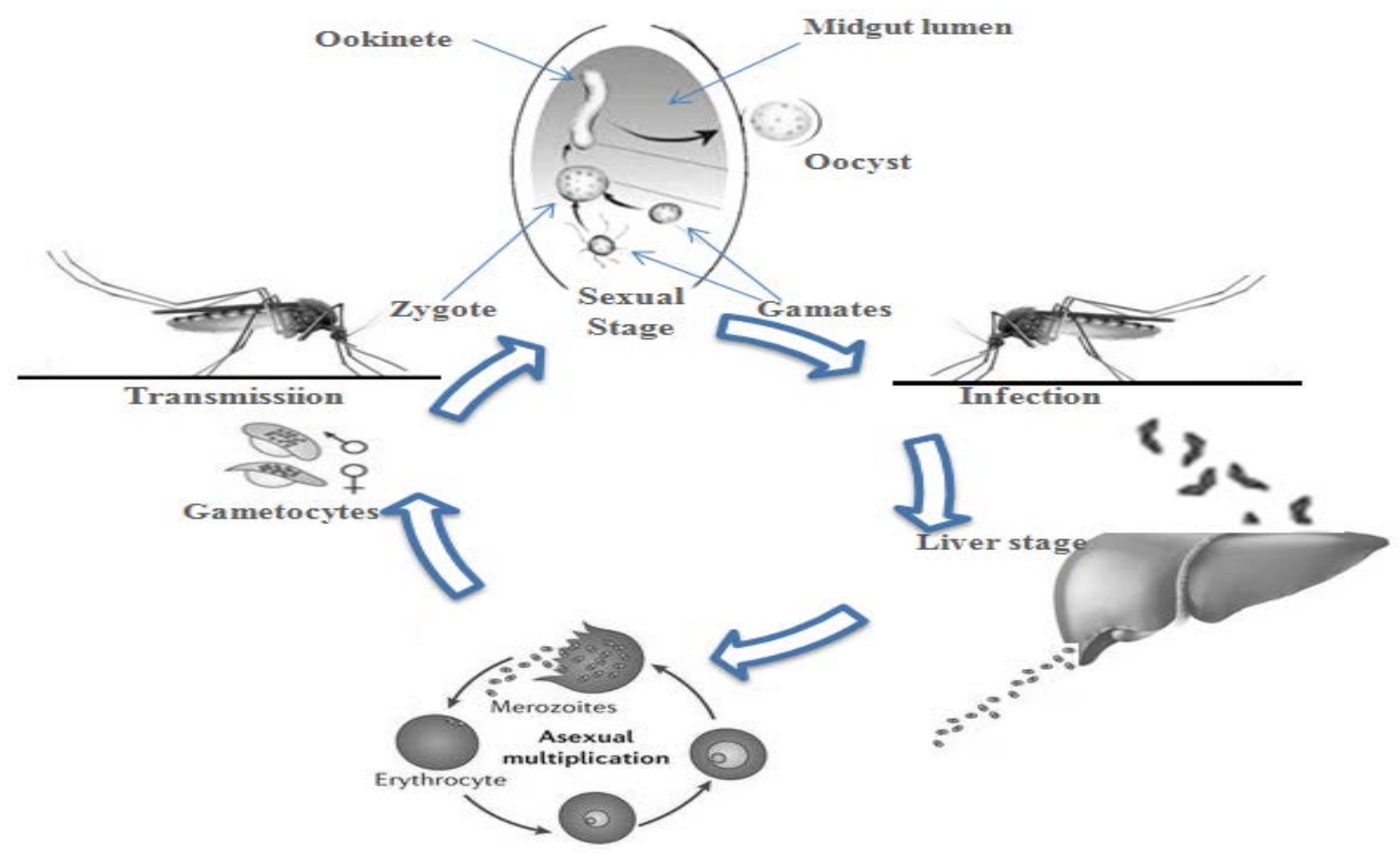

Figure 1: Life cycle of the malaria parasite<smiles>C=CC1CC2CCC1N2C(O)c1ccnc2ccc(OC)cc12</smiles>

1<smiles>CCN(CC)CCCC(C)Nc1ccnc2cc(Cl)ccc12</smiles>

2<smiles>CCN(CC)Cc1cc(Nc2ccnc3ccccc23)ccc1O</smiles>

3<smiles></smiles><smiles>COc1cc(NCCCC(C)N)c2ncccc2c1</smiles>

Figure 2: Chemical structures of some quinoline derivatives 
<smiles>CCc1nc(N)nc(N)c1-c1ccc(Cl)cc1</smiles><smiles>CC(C)NC(=N)NC(=N)Cc1ccc(Cl)cc1</smiles><smiles>CC(C)CNC(=N)NC(=N)N/C=C1/C=C(Cl)C(Cl)=CC1</smiles><smiles>COc1cc(Cc2cnc(N)nc2N)cc(OC)c1OC</smiles><smiles>COc1ncnc(NS(=O)(=O)c2ccc(N)cc2)c1OC</smiles>

10

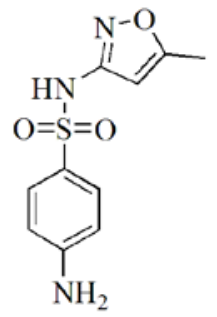

11

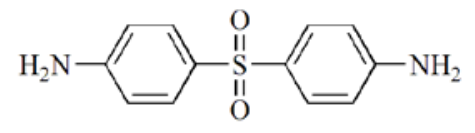

12

Figure 3: Chemical structures of antifolate drugs<smiles>CN(C)[C@@H]1C(O)=C(C(N)=O)C(=O)[C@]2(O)C(O)=C3C(=O)c4c(O)cccc4[C@@](C)(O)C3CC12</smiles>

13<smiles>CN(C)C1C(O)=C(C(N)=O)C(=O)[C@@]2(O)C(O)=C3C(=O)c4c(O)cccc4C(=O)C3CC12O</smiles>

14<smiles>[CH]C([CH])C(NC(=O)[C@H]1CC(CCC)CN1C)[C@H]1O[C@H](SC)[C@@H](O)[C@H](O)[C@H]1O</smiles>

15

Figure 4: Chemical structures of antimalarial antibiotics<smiles>C[C@H]1CC[C@H]2[C@@H](C)C(=O)C[C@H]3CCC4(C)OO[C@]23[C@@H]14</smiles>

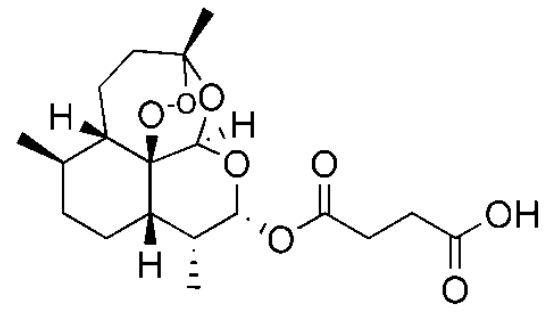

17

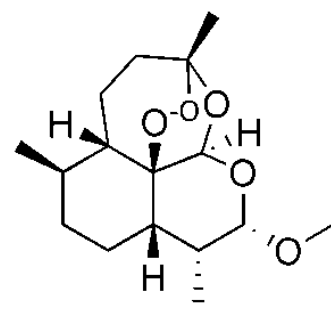

18

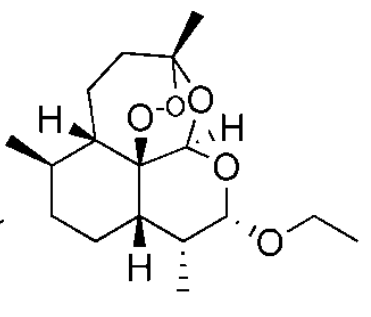

19

Figure 5: Chemical structures of artemisinin and related compounds 


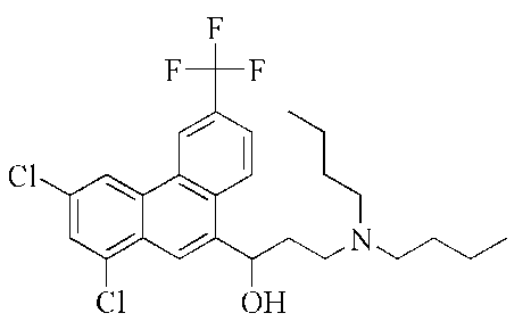

20

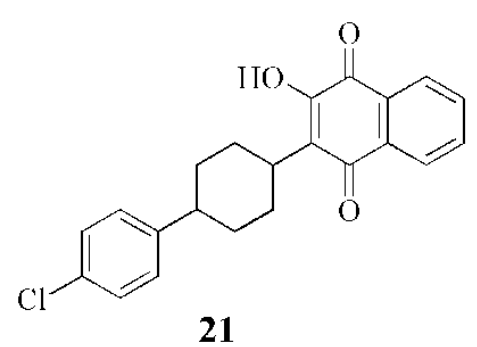

21

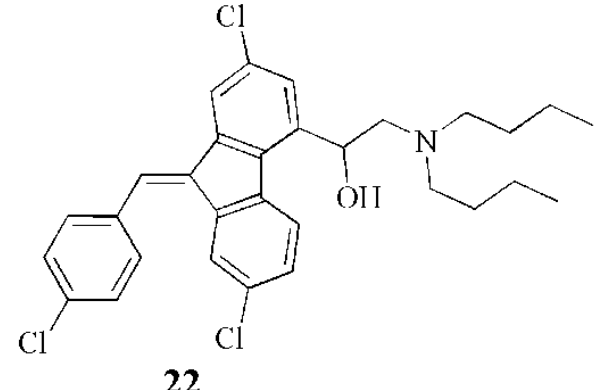

22

Figure 6: Chemical structures of napthoquinone, phenanthrene and fluoromethanol derivatives

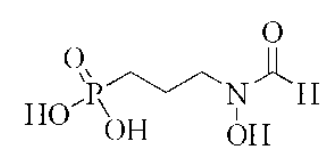

23

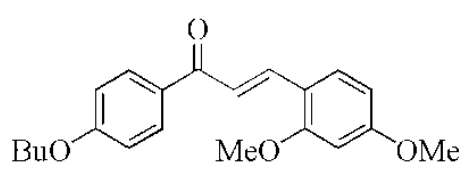

24

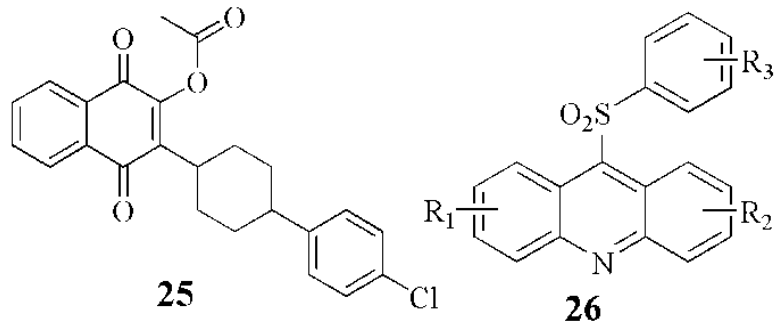

25

Figure 7: Chemical structures of fosmidomycin, chalcone, naphthoquinone and arylsulfonyl acridinyl derivatives<smiles>CC1(C)N=C(N)N=C(N)N1OCCCOc1cc(Cl)c(Cl)cc1Cl</smiles>

27<smiles>CCC1N=C(N)N=C(N)N1OCCCOc1ccccc1CCC(=O)[O-]</smiles>

28

Figure 8: DHFR inhibitors 
<smiles>C=NNCc1ccc(C(=O)c2cccc(Cl)c2)cc1</smiles><smiles></smiles><smiles>[R]NC(=[R])NONc1ccnc2cc(Cl)ccc12</smiles><smiles>CC(C)(C)NCCNc1cc[n+]([As])c2cc(C(F)(F)F)ccc12</smiles>

Figure 9: 4-aminoquinoline antimalarials

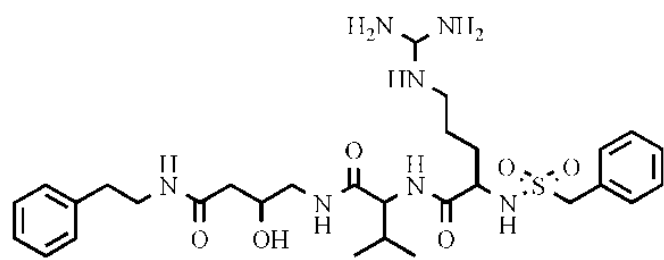

34<smiles>Cc1cc(NC(=O)Nc2cc(Cl)c(Oc3ccc(Cl)cc3)cc2[N+](=O)[O-])ccc1Cl</smiles>

36

Figure 10: Plasmepsin inhibitors 
<smiles>O=C(C[C@@H]1NCCC[C@H]1O)Cn1cnc2ccc(O)cc2c1=O</smiles><smiles>O=c1c2cc(O)ccc2ncn1C[C@@]1(O)C[C@@H]2NCCC[C@H]2O1</smiles><smiles>O=C(CC1NCCCC1O)Cn1cnc2cccnc2c1=O</smiles><smiles>O=C(CC1NCCCC1O)Cn1cnc2ccc(F)c(F)c2c1=O</smiles><smiles>O=C(CC1NCCCC1O)Cn1cnc2ccsc2c1=O</smiles><smiles>O=C(CC1NCCCC1O)Cn1cnc2ccc(F)cc2c1=O</smiles><smiles>O=C(CC1NCCCC1O)Cn1cnc2ccccc2c1=O</smiles><smiles>O=C(CC1NCCCC1O)Cn1cnc2nc[nH]c2c1=O</smiles><smiles>Nc1ccccc1C(=O)N(N)CC(=O)CC1NCCCC1O</smiles><smiles>O=C(CC1NCCCC1O)Cn1ccc(=O)c2ccccc21</smiles>

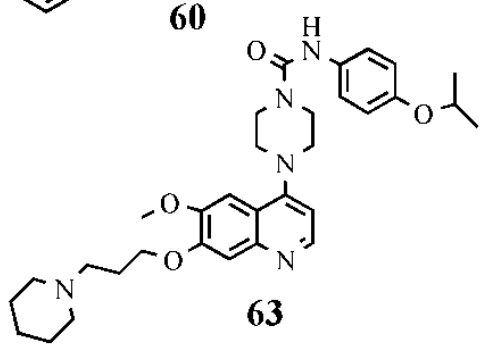<smiles>CNc1cc2[nH]c(=O)n(-c3ccc(NC(=O)NS(=O)(=O)c4ccc(Cl)s4)cc3)c(=O)c2cc1F</smiles>

Figure 11: Quinazolines, Quinazolinones and analogues of febrifugine 